\title{
POETRY SLAM: POR UMA COMUNIDADE QUE VEM
}

\section{POETRY SLAM: BY A COMMUNITY THAT COMES}

\author{
Gabrielle Forster ${ }^{1}$ \\ Universidade Federal de Santa Maria
}

Resumo: Com sua performance corporal, seu ludismo e o desejo de partilha na esfera comum e cotidiana, o poetry slam se manifesta como expressão poética resistente tanto no âmbito dos temas quanto das formas, inovando os lugares de fala e os veículos de circulação do literário. Como acontecimento plural e democrático, fundado na experiência aberta do encontro e na tomada dos lugares de fala silenciados e marginalizados, os slams poéticos veiculam uma forma de comunidade diferenciada: inoperante, inconfessável e impossível, na linha das reflexões propostas por autores como Jean-Luc Nancy, Esposito, Blanchot e Agamben. Na desconstrução da acepção moderna de comunidade, tomada como núcleo atributivo e homogêneo, reside sua capacidade de resistência, enquanto renovadora de espaços, discursos e existências.

Palavras-Chave: Poetry slam; Comunidade; Resistência.

\footnotetext{
1 Endereço eletrônico: gabrielle.zac.forster@gmail.com.
} 
Abstract: With its bodily performance, its ludic and the desire to share in the common and everyday sphere, the poetry slam manifests itself as a resistant poetic expression both in terms of themes and forms, innovating the places of speech and the vehicles of literary circulation. As a plural and democratic event, based on the open experience of the encounter and on the silenced and marginalized places of speech taken, the poetic slams convey a differentiated form of community: inoperative, inadmissible and impossible, in line with the reflections proposed by authors such as Jean-Luc Nancy, Esposito, Blanchot and Agamben. In the deconstruction of the modern meaning of community, taken as an attributive and homogeneous nucleus, lies its resilience, as a renewer of spaces, discourses and existences.

Keywords: Poetry Slam; Community; Resistance.

A poesia respira, desborda-se, toma seu corpo, o meu corpo, atravessa as páginas, alcança as ruas, recobra a voz, inverte o jogo, convida. Dos espaços públicos de grande circulação cresce o som dessa voz coletiva que se alça como uma batida, uma pulsação, um alarme de que a poesia não tem dono, nem patrão, nem casa, nem hierarquia, a poesia é nossa, a poesia é vida. E não está sozinha, nem pode ser silenciada. Ela rebenta. Além do cânone, das instituições, da letra erudita, ela vive.

Tal vitalismo que a poesia dos slams reverbera, com sua performance corporal, seu ludismo, sua expressão presentificada e o desejo de partilha na esfera comum, cotidiana, pode ser reconhecido como um sintoma das modificações sociais experimentadas na contemporaneidade, e que, segundo Maffesoli, põe em marcha uma pulsão nômade e dionisíaca, uma paixão comunitária, uma socialidade empática, "un pensamiento del vientre. Un pensamiento que sepa encargarse de los sentidos, las pasiones y las emociones comunes" (MAFFESOLI, 2004, p. 24).

A proposta dos slams se funda na experiência aberta do encontro e na possibilidade da autorrepresentação e da tomada dos lugares de fala silenciados e marginalizados, unindo arte e vida, ética e estética. Aqui, "o texto não é o produto final da atividade criativa, mas um ato de intervenção e participação na vida da comunidade onde ele se produz e circula" (OLIVEIRA, 2011, p. 34). 
Assim, apropria-se de um bem simbólico que lhe foi negado e lhe dá novas feições, ao mesmo tempo que possibilita a circulação de expressões identitárias contra-hegemônicas, rompendo com estereótipos excludentes e cristalizados. Tal vitalismo, que se eleva como um movimento periférico em relação aos padrões sociais e às próprias estruturas e convenções da língua e do literário, mostra que:

nada pode fazer calar a fala necessária. Não se podem queimar as palavras que, precisamente, tentam falar da urgência da fala perdida e reencontrada. E todos os poderes reunidos nada podem, afinal, contra a força básica que corre subterraneamente pelo corpo social e irriga-o em profundidade. (MAFFESOLI, 2009, p. 28)

Os eventos, que iniciaram nos Estados Unidos na década de 90 e se disseminaram no Brasil a partir de 2008, desde que Roberta Estrela D'Alva fundou o ZAP!, em São Paulo, buscam, como a própria onomatopeia que o denomina sugere, instaurar uma zona autônoma da palavra. Espalhados agora por várias regiões periféricas do país e intitulados com variados nomes, se assumem como um acontecimento plural e democrático, que se propõe a dar voz a todo aquele que quiser valer-se da palavra.

Neles, o papel do leitor/ouvinte é explicitamente ativo: inspirados a manifestar-se de acordo com o frenesi causado pelas performances poéticas, podem atuar também como jurados ou inscrever-se como slamers, combatendo, é claro, com palavras e pela poesia. Por isso, como explica D'Alva:

a diferença de estilos, discursos, idades é característica marcante, e numa noite podem-se ter, juntos, disputando o mesmo slam, estudantes, adolescentes, professores, atores, profissionais liberais, MCs, jornalistas, donas de casa, dançarinos, vendedores ambulantes, todos reunidos em torno de um único microfone, fazendo uso da liberdade de expressão das suas ideias. (D'ALVA, 2011, p. 125)

É na esteira da horizontalidade, reconhecida por Maffesoli como mais uma das características das tribos pós-modernas, que se configuram os slams, 
reverberando o prazer de estar juntos, a liberdade da palavra, o desejo de compartilhar afetos, histórias, experiências, repertórios, dores e sonhos, para encontrar novas formas de solidariedade, de afetividade, outras maneiras de estar junto.

Não há como negar o caráter inclusivo e libertário de um encontro de poetry slam [...] É um espaço para que o sagrado direito à liberdade de expressão, o livre pensamento e o diálogo entre as diferenças sejam exercitados. Um espaço autônomo onde é celebrada a palavra, a fala, e, ainda mais fundamental num mundo como o que vivemos - a escuta. (D'ALVA, 2011, p. 125)

Assim, contra o universalismo moderno e seu modelo vertical e androcêntrico, vemos despontar uma pluralidade de vozes, convergentes na diversidade e na luta pelo direito de expressar a própria voz, longe das recorrentes marginalizações e capturas. Com temáticas variadas, que perpassam experiências e vivências cotidianas compartilháveis, o conjunto dessas poesias se conecta pelo teor resistente, deslegitimador e revolucionário.

Para observar isso, foram escolhidas sete poesias, encontradas, sobretudo, no canal Manos e Minas, do youtube. A escolha de tal corpus se baseou na abordagem desconstrutora de lugares e corpos empreendida pelo viés da interseccionalidade. Temas recorrentes nos slams, como as questões de gênero, raça e sexualidade, assim como os conflitos centro/periferia, podem ser observados por meio dos exemplos trazidos, mas é bom ressaltar que a necessidade do recorte é apenas textual, visto não ser possível dar conta de um corpus muito extenso nesse espaço. Ou seja, a qualidade e a reflexão crítica que encontramos nessas poesias podem ser observadas em todo o movimento, de modo que ao longo do trabalho também optamos por mencionar a produção em seu conjunto.

Nessas poesias, os múltiplos aspectos que envolvem as formas de opressão, preconceito e silenciamento impostas aos grupos considerados 
minoritários são explorados com o intuito de ressignificar os espaços, as representações e as relações. Aqui, a denúncia do feminicídio, do racismo, da homofobia, da miséria e do isolamento social se coloca ao lado de uma força vital que reivindica a todo momento o seu direito de existência e expressão, reconfigurando as imagens, os corpos e as possibilidades de experiência.

Por meio da exposição de uma dura realidade que sempre se há buscado silenciar e esconder, essa poesia questiona e critica o sistema hegemônico opressor e a desigualdade sobre a qual se constroem as cidades e a nação, ao mesmo tempo que reinventa os espaços e reconfigura as subjetividades, possibilitando a afirmação de um reconhecimento longe dos estigmas. Assim, exalta a beleza e a cultura negra, a liberdade do corpo e da experiência da mulher, as múltiplas formas de amor e de família, e afirma outras possibilidades de existência longe dos estereótipos destinados aos habitantes da periferia. A poesia nos slams é usada para ferir e para salvar. É quase impossível sair imune da ferocidade dessa batida. E depois respiramos com a amplitude do horizonte que ela abre.

Indissociável da performance de cada poeta, essa poesia resiste pelos temas, mas também pela forma, na esteira da "ressurgência das energias vocais da humanidade, energias que foram reprimidas durante séculos no discurso social das sociedades ocidentais pelo curso hegemônico da escrita" (ZUMTHOR, 2002, p. 15). Nos slams a poesia é palavra, mas inseparável do corpo, da expressão e da apresentação, da voz. Uma voz viva que, segundo Paul Zumthor, "tem necessidade - uma necessidade vital - de revanche, de "tomar a palavra, como se diz" (ZUMTHOR, 2002, p. 16).

É pela performance que essa poesia resiste, acontece e atua sobre o presente, já que envolve "a presença concreta de participantes implicados nesse ato de maneira imediata" (ZUMTHOR, 2002, p. 50). Não há como separá-la da 
apresentação do poeta, da sua voz, da teatralidade de seu corpo, nem das reações e da energia da plateia, pois

corpo e voz, simultaneamente, dão o tom do espetáculo performático. Alguns poetas declamam no palco, alternando o uso ou não do microfone; outros caminham por entre a plateia, gesticulam, gritam e silenciam, incorporando os poemas de cor e par couer. (NEVES, 2017, p. 102-103)

Por isso, como bem observa Neves (2017), esses encontros põem em circulação o caráter dialógico da linguagem, explicitando essa resposta ativa e responsiva que os estudos de Bakhtin colocam em evidência, já que "no caso dos slams, essa resposta não se restringe às notas do júri, mas, também, e principalmente, à reação do público ouvinte" (NEVES, 2017, p. 101).

A poesia dos slams é algo que se configura no evento e que se faz sob uma multiplicidade de aspectos envolvidos nesse acontecimento singular. Assim, torna-se "motor essencial da energia coletiva" (ZUMTHOR, 2002, p. 63), na esteira de uma nova era da oralidade, que o autor citado observa. Por isso, o que ela comunica se coloca para além da informação passada, já que seu efeito age diretamente sobre o público, numa espécie de catarse coletiva que desconstrói paradigmas por meio da própria experiência sensorial.

Por isso, ainda que muitas vezes o tema dessas poesias seja doloroso, envolvendo miséria e violência, o que se ressalta nos eventos é a alegria da festa, do encontro. A alegria de poder compartilhar, de gastar-se, exceder-se, por todos os poros, pela poesia. E a festa é sempre uma maneira de burlar as regras sociais pautadas no acúmulo, na racionalização, na ordem.

Nos encontros propiciados pelos slams, o festivo e o lúdico são elementos essenciais e a regra hierárquica do jogo é invertida, pois ainda que ao final tenhamos um vencedor, a participação é sempre o elemento que se ressalta. Nesse sentido, é inegável que sua realização é a expressão de uma modificação social que vem sendo engendrada, e na qual “[...] frente à anemia existencial 
provocada por um social demasiado racionalizado, as tribos urbanas destacam a urgência de uma sociabilidade empática: compartilhar emoções, compartilhar afetos"' (MAFFESOLI, 2004, p. 20, tradução própria)². Por isso, nesses encontros:

o centro da cidade se torna palco de dramas que são ao mesmo tempo pessoais e coletivos. A prática da cidadania insurgente acontece, então, no centro da polis, na ágora, no fórum, e toma a praça, quebrando a lógica de funcionamento da cidade neoliberal, reclamando o espaço da cidade enquanto espaço de festa e manifestação. (FREITAS, 2020, p. 13)

Entretanto, percebe-se que, embora a proposta dos slams seja a partilha de experiências e de expressões originadas e advindas de vivências e existências periféricas, a noção de comunidade que ela veicula não busca a configuração de um núcleo comunitário, um laço identificador homogeneizante, que unificaria o conjunto, mas descontrói essa própria possibilidade em prol da afirmação de um "com-partilhar" que se faz no encontro com o outro. Essas poesias enunciam-se desde as margens, mas colocam-se além dessa captura, evitando os clichês e os mitos dentro dos quais foram capturadas. Aqui, cada voz que se eleva é uma experiência única, que traça um ponto de encontro justamente na exposição ao outro, no convite a escutar a pluralidade e a diferença como constitutivas do estar junto.

Nesse sentido, não se trata de fundar uma comunidade, mas de repensar a própria configuração desta, cuja necessidade se coloca na esteira de algumas propostas que, ao reconhecer os prejuízos produzidos em nome do "comum", se dispuseram a questionar e redefinir o conceito mesmo de comunitário. Nessa empreitada, da qual participam Jean-Luc Nancy, Blanchot, Agamben e Esposito, a noção tradicional de comunidade é deslocada na medida em que neste âmbito de reflexão o termo não encerra mais em si um núcleo comunitário, unificante e

\footnotetext{
2 No original: “[...] frente a la anemia existencial suscitada por un social demasiado racionalizado, las tribus urbanas destacan la urgencia de una socialidad empática: compartir emociones, compartir afectos" (MAFFESOLI, 2004, p. 20).
} 
totalizante, a partir do qual as relações estabelecidas se dariam sob a forma do Mesmo, mas aponta para uma comunidade (im)possível, marcada de alteridade ao se ver dispersa pela presença desconcertante e dissimétrica do Outro, do radicalmente outro, mantido em sua irredutibilidade ao igual. Logo,

Se a relação do homem com o homem deixa de ser a relação do Mesmo com o Mesmo introduzindo ao Outro como irredutível e, em sua igualdade, sempre em dissimetria com aquele que o considera, se impõe um tipo de relação totalmente distinto e se impõe outra forma de sociedade que apenas se ousará denominar comunidade. Ou se aceitará chamá-la assim perguntando-se o que está em jogo no pensamento de uma comunidade e se esta, havendo existido ou não, não propõe sempre, e por fim, a ausência de comunidade. (BLANCHOT, 2002, p. 13, tradução própria) ${ }^{3}$

Se a experiência da comunidade é estar-em-comum, como propõe Nancy, pensá-la com os termos essencialistas, totalizantes e fechados, que tanto nos custaram e seguem a fazê-lo, é alterar, deformar a sua informidade, a sua impropriedade. "Somos semelhantes porque estamos, cada um de nós, expostos ao desconhecido que nós somos para nós mesmos" (NANCY, 2000, p. 44, tradução própria) ${ }^{4}$. Logo, compartilhar não é apropriar-se. Não é unir-se por atributo, somar-se na posse de um traço identificatório, mas abertura e dobra; devir entre essa repartição. Por isso,

Não existe entidade nem hipóstase da comunidade, porque essa partilha, esse trânsito é inacabável. O inacabamento é o seu «princípio» - mas no sentido em que o inacabamento deveria ser tomado como um termo ativo, designando não a insuficiência ou a falta, mas atividade da partilha, a dinâmica, se se pode dizer, do trânsito ininterrupto pelas rupturas singulares. Vale dizer, outra vez, uma atividade inoperante. Não se trata de

3 No original: "si la relación del hombre con el hombre deja de ser la relación del Mismo con el Mismo introduciendo al Otro como irreductible y, en su igualdad, siempre en disimetría con aquel que lo considera, se impone una clase de relación totalmente distinta e impone otra forma de sociedad que apenas se osará denominar comunidad. O se aceptará llamarla así preguntándose lo que está en juego en el pensamiento de una comunidad y si esta, haya existido o no, no plantea siempre al final la ausencia de comunidad" (BLANCHOT, 2002, p. 13).

4 No original: "Somos semejantes porque estamos, cada uno, expuestos al afuera que somos nosotros para nosotros-mismos" (NANCY, 2000, p. 44, grifo do autor). 
fazer, nem de produzir, nem de instalar uma comunidade; menos ainda de venerar ou de temer um poder sagrado nela. Se trata de inacabar a sua partilha. (NANCY, 2000, p. 46, tradução própria) ${ }^{5}$

Assim, na iminência de uma "comunidade que vem" (Agamben), de uma comunidade "inconfessável" (Blanchot) e "inoperante" (Nancy), o compartilhar se vê dessubstancializado na direção de um contato que expropria os participantes, colocando-os em estado de perda: expostos pela repartição. Dessa forma, rompe-se com os atributos de identificação em nome dos quais se considerou até então a comunidade, apontando para uma configuração que extravasa os parâmetros excludentes e devastadores de tudo aquilo que não se enquadra no conjunto "a preservar", agrupe este: raça, território, partido político, religião, gênero ou o que queira unificar. Ou seja, trata-se de pensar a comunidade na própria recusa da comunhão identitária que a configurou em sua acepção moderna e que no fundo serviu para mecanismos de controle e segregação que invalidam a sua possibilidade.

Ainda que muitos slams viabilizem a circulação de vozes advindas de grupos marginalizados, o que se percebe é uma variedade de expressões que quebra qualquer tentativa de homogeneizar e mitificar um conjunto. A proposta não é inverter a relação eu/outros, centro/periferia, mas rachar esse binômio, transbordar as margens, desterritorializá-las. Nas performances poéticas observa-se que não há busca por uma essência como fundamento unitário e fusional de um tipo de comunidade, mas exposição ao outro, abertura contínua à diferença. Por isso a rica variedade de abordagens de experiências de sujeitos

\footnotetext{
5 No original: "no hay entidad ni hipóstasis de la comunidad, porque este reparto, este tránsito es inacabable. El inacabamiento es su «principio» - pero en el sentido en que el inacabamiento debería ser tomado como un término activo, designando no la insuficiencia o la falta, sino la actividad del reparto, la dinámica, si puede decirse, del tránsito ininterrumpido por las rupturas singulares. Vale decir, otra vez, una actividad inoperante. No se trata de hacer, ni de producir, ni de instalar una comunidad; tampoco se trata de venerar o de temer un poder sagrado en ella. Se trata de inacabar su reparto" (NANCY, 2000, p. 46).
} 
que, embora compartilhem lugares de fala comuns, tocam-nos com a singularidade de sua poesia e perspectiva.

Nesse sentido, podemos dizer que a paixão comunitária vitalizada pelos slams difere da noção usual de comunidade, cuja busca de pertencimento recai em totalizações. Seu convite, ao contrário, é como "um dom para renovar, para comunicar, não é uma obra a ser feita" (NANCY, 2000, p. 47, tradução própria) ${ }^{6}$, porque não busca configurar ou restaurar uma essência prévia, um ser comum a todos, que acabaria eliminando as diferenças, mas aposta na abertura propiciada pelo encontro como condição que questiona o próprio pertencimento. Assim, insinua-se em cada performance uma ética da alteridade, que resiste à modelagem dogmática para enfatizar a potência constitutiva e positiva do infinitivo encontrar.

Em tal abertura é que pode efetivar-se, como indica Agamben, a experiência ética, ou seja, na não obrigatoriedade de encarnar uma essência ou cumprir um destino, pois "há, de facto, algo que o homem é e tem de ser, mas este algo não é uma essência, não é propriamente uma coisa: é o simples facto da sua própria existência como possibilidade ou potência" (AGAMBEN, 1993, p. 38, grifo do autor). Desse modo, o que se ressalta é a experimentação enquanto via de acesso a estados inusitados do sensível, em detrimento da assimilação de uma característica vinculativa que destrói o dissenso e a diversidade irrevogável de nossa condição de ser-com. Em cada voz que se escuta num poetry slam surge uma possibilidade de contágio que não busca a configuração de um vínculo fusional, mas o questionamento dos próprios modelos que estabelecem as separações comunitárias.

Se tomamos, com Esposito, a origem latina da palavra, descobrimos que ela já aponta para uma compreensão diferente de comunidade, avessa à noção de

\footnotetext{
6 No original: "[...] un don para renovar, para comunicar, no es no es una obra que hacer" (NANCY, 2000, p. 47).
} 
pertença que recai na captura do outro em seu eterno retorno ao mesmo. De acordo com o autor "[...] communitas é o conjunto de pessoas unidas não por uma propriedade, mas justamente por um dever ou uma dívida. Conjunto de pessoas unidas não por um mais, mas por um menos, uma falta" (ESPOSITO, 2003, p. 2930, tradução própria) $)^{7}$ Enquanto o radical cum marca a repartição com o alheio, o contorno do entrecruzamento mútuo, a exposição ao outro, "el munus que la communitas compartilha não é uma propriedade ou um pertencimento. Não é uma apropriação; ao contrário, é uma dívida, um presente, um dom a doar" (ESPOSITO, 2003, p. 30, tradução própria) ${ }^{8}$, que impede justamente a constituição de uma substância comunitária, de um predicado próprio como diretriz para a configuração do conjunto. Desse modo, se anuncia uma noção dissonante de comunidade, ou seja,

[...] não é o próprio, mas o impróprio - ou, mais drasticamente, o outro - o que caracteriza ao comum. Um esvaziamento, parcial ou integral, da propriedade em seu contrário. Uma desapropriação que investe e descentra ao sujeito proprietário e lhe força a sair de si mesmo. A alterar-se. (ESPOSITO, 2003, p. 31, tradução própria) ${ }^{9}$

Pensada como contágio que elimina toda a pretensão de essência, a silhueta dessa comunidade é a borda flexível cujo movimento perpétuo impede a fixação, a curvatura maleável que nos descentra e extravia no contato: repartição que revoga parâmetros de completude e integridade subjetiva. Por isso, no impresumível dessa comunidade, reclamada em sua falta constitutiva, não há

\footnotetext{
7 No original: "[...] communitas es el conjunto de personas a las que une, no una propiedad, sino justamente un deber o una deuda. Conjunto de personas unidas no por un más, sino por un menos, una falta (ESPOSITO, 2003, p. 29-30).

8 No original: "el munus que la communitas comparte no es una propiedad o pertenencia. No es una posesión, sino, por el contrário, una deuda, una prenda, un don-a-dar" (ESPOSITO, 2003, p. 30).

9 No original: "no es lo propio, sino lo impropio - o, más drásticamente, lo otro - lo que caracteriza a lo común. Un vaciamiento, parcial o integral, de la propiedad en su contrario. Una desapropiación que inviste y descentra al sujeto propietario y lo fuerza a salir de sí mismo. A alterarse" (ESPOSITO, 2003, p. 31).
} 
forma de comunhão a ser resgatada, nem projeto de nova união atributiva, mas abertura a um espaço nômade de experimentação, de variação, de possíveis contágios, que invalidam modelos comunitários pautados em identificações totalizadoras e homogêneas, pois, permeado de contingência, o "estar-com" se vê marcado de alteridade, de dissenso, de pluralidade, de potencialidades. A cada encontro uma dobra, uma possibilidade que se abre: um poder de afetar e de ser afetado que se investe contra a estabilidade identitária.

Nessa perspectiva deve ser pensado o conjunto de vozes que se entrecruzam nos slams, já que elas não se unem por atributos estáveis, mas compartilham a ânsia pela desconstrução de tais atributos que repercutem em modelos de opressão. O periférico, desde seus múltiplos espaços de marginalização, não é algo a ser configurado, mas questionado, rachado na pluralidade das possibilidades de expressão.

A aposta é na experiência, existencial, corporal, poética: testar as possibilidades subjetivas, tencionar os discursos opressivos elaborados sobre as mesmas, reinventar as situações num acontecimento direto e certeiro. O poetry slam é revolucionário em sua própria presença e atualidade. Não se move na direção de um ideal utópico, mas transforma a própria realidade à medida que a enuncia desde outra perspectiva.

Muitas poesias recorrem ao produtivo diálogo com a História para desvelar nossa rica constituição miscigenada, porém massacrada, saqueada, sofridamente desigual. Não sugerem uma solução ou impõe uma ação orientada, mas apostam na tomada de consciência como força que se move na direção contrária à alienação. Parodiar o hino da "pátria safada" que nos pariu, como faz o slamer Michel cena 7 (2018), ou negar-se, com a voz de Luiza Romão (2016) a escrever "Brasil", nome mercadoria, palco de abusos e monstruosidades desde a colonização, é no mínimo não compactuar, inscrevendo uma realidade que 
destapa nossos olhos para os confins das regiões e existências oprimidas e ignoradas.

A denúncia das recorrentes desigualdades, que se expressam inclusive na segregação urbana, como demonstra a slamer Midria (2018) em sua observação de uma São Paulo dividida e excludente, não buscam a vitimização, nem a proposta de ações sociais para levar as margens aos centros. $\mathrm{O}$ desejo não é o centro e a inversão de papéis, mas o movimento de retomada de seus lugares de fala e existência ignorados e silenciados, conforme mostra a configuração do próprio evento, que se apropria de algo que já é seu: a voz, o corpo, a cultura, a arte. Como bem anuncia Sérgio Vaz, em seu Manifesto da Antropofagia Periférica, “a arte que liberta não pode vir da mão que escraviza” (VAZ, 2011, online). Logo,

é preciso sugar da arte um novo tipo de artista: o artista-cidadão. Aquele que na sua arte não revoluciona o mundo, mas também não compactua com a mediocridade que imbeciliza um povo desprovido de oportunidades. (VAZ, 2011, online)

Nesse sentido se constrói a poesia dos slams, cuja batida encontra nas fontes populares, desprestigiadas pela Academia, a potência de sua voz como alternativa aos modelos que não lhe cabem, aos discursos que não lhe configuram, à realidade desfigurada que exclui e ignora a sua participação. Ao apontar "para uma redistribuição polêmica das maneiras de ser e das 'ocupações' num espaço de possíveis" (RANCIÈRE, 2005, p. 63), a periferia do slam vai além de espaços e situações; ela é um movimento subterrâneo, que desmascara e faz vazar a lógica opressiva e ao mesmo tempo produtiva do poder, em sua banalização modelar da vida. Portanto, no resgate de sua visibilidade e valor, e na denúncia do intolerável que faz vergar a vida na direção de uma transmutação afetiva, reside sua atividade política, entendida, com Rancière, como aquela 
que desloca um corpo do lugar que era designado ou muda a destinação de um lugar; ela faz ver o que não cabia ser visto, faz ouvir um discurso ali onde só tinha lugar o barulho, faz ouvir como discurso o que só tinha lugar como barulho. (RANCIÈRE, 1996, p. 42)

Ao compreender a política como contagem das partes ao invés de estabelecimento de vínculos, o referido pensador considera que nesse cálculo há sempre uma margem de erro e é ela que permite que haja "política - e não simplesmente dominação - porque há uma conta malfeita nas partes do todo" (RANCIÈRE, 1996, p. 25). Do reconhecimento de uma parcela dos sem parcela daquilo que escapa à contagem por não poder ser inserido nas definições categóricas dadas de antemão, ultrapassando as funções pré-determinadas, excedendo a esfera do discurso que lhe compete ou vazando dos contornos identitários fechados - é que nasce a política.

Seu fundamento está na relação oposta que estabelece com a polícia, termo ao qual Rancière recorre não para referir-se à corporação policial ou à atividade de proteção cívica, mas para conceituar "uma ordem do visível e do dizível que faz com que essa atividade seja visível e outra não o seja, que essa palavra seja entendida como discurso e outra como ruído" (RANCIÈRE, 1996, p. 42). Por conseguinte, a intersecção entre arte e política reside na sua capacidade de desestabilizar essa ordem articulada a partir do desentendimento suscitado pela inserção de uma percepção distinta que intervém nas divisões vigentes, tornando visível o que antes não tinha lugar no comum partilhado.

Dissonância que se ativa tanto nas performances poéticas dos slams quanto na própria forma de composição do evento e circulação do literário. Não há como negar que a batida do poetry slam é um ruído que faz a poesia escapar da categoria na qual estava pressuposta e que cada voz que ali se enuncia tem o poder de suscitar uma transformação afetiva enquanto possível desclassificador de formas-de-vida que não lhes são suficientes, forçando, em consequência, à reinvenção desses lugares e corpos. 
Quando o slamer Felipe Marinho diz que “a coisa tá preta, mas tão preta que nada mais vai passar em branco" (MARINHO, 2018), refere-se a essa tomada de consciência que se move na direção de uma reconfiguração dos espaços e existências, não mais enclausurados nos estereótipos de dominação. O que antes era sufocado é ruído que agora se faz discurso em alto tom na praça pública. Por isso a necessidade de apropriar-se das palavras de ordem e das imagens preconceituosas como denúncia daquilo que não pode definir a vida em sua riqueza, amplitude e potência. Ao recorrer aos estigmas de marginalização, assumindo-se como "aquele neguinho de quem você esconde a bolsa" (MARINHO, 2018), desprestigiado "por sua suposta cara de marginal" (MARINHO, 2018), e ao qual recai o peso da escravidão prolongada pelos "furos da lei Áurea" (MARINHO, 2018), ressignifica essas mesmas imagens e posições, rachando a "naturalização" engendrada pela lógica opressiva.

É preciso retomar as imagens que nos capturam para desconstruir a força de sua convenção e abrir a possibilidade de criação de novos espaços, relações e experiências. Nesse sentido se constroem muitas das performances poéticas cujo tema se volta para as mulheres e suas vivências. A partir da menção às palavras ofensivas e aos papéis que lhe são destinados, elas propõem uma rematerialização desses corpos e espaços, tornando audível o silêncio produzido pelo falocentrismo. Na ironia que jaz por trás dos agradecimentos de Isabela Penov (2016) a um sistema que configurou o feminino como passivo, dócil, objetalizado, sujeito a abusos diversos, reside a força de sua poesia como crítica aos aparatos de dominação que não só controlam, mas também produzem os corpos que governam, como nos ensinou Foucault.

Conforme lhe exigem as regras do patriarcado, ela agradece e se enuncia como merecedora das violações infringidas ao corpo coletivo feminino, assumindo o papel que se espera dentro desse sistema, para tornar evidente a força construtora da opressão. Quantas mulheres ainda são submetidas a essas 
convenções naturalizadas que sustentam a lógica de um sistema dominantemente masculino e heterossexual? E "engolem" "os elogios", as definições inferiorizadas, a submissão e a apropriação de seu corpo, como se fosse algo ao qual bem se ajusta o seu ser "menor"? Ao assumir a posição subalterna adquirida na dicotomia hierárquica entre os sexos, que impõe às mulheres a obrigação de reproduzir e servir, encarnando determinados estereótipos dentro dessa relação binária, desconcerta o ouvinte pelo deslocamento e alcance do discurso patriarcal, imiscuído inclusive na perspectiva do oprimido.

Ainda que sejam valiosas todas as conquistas e as modificações abertas pela teoria crítica feminista em relação à compreensão do discurso produtor de gênero, é inegável que a força da convenção opressora se naturaliza e persevera ainda hoje. É a esse corpo feminino, apropriado pela indústria pornográfica, destituído de seu próprio prazer, subjugado, inferiorizado e violado em tantos becos e casas, que ela se refere, mostrando que toda essa violência tem por trás um discurso machista que se ergue com tanta força, a ponto de podermos ouvir, em alto tom e em canal aberto, como a poeta relembra, "a sentença" de uma jornalista cujo corpo, segundo o nosso atual presidente, não merece ser estuprado, como se a objetalização e a sexualização do feminino permitisse tal monstruosidade.

Por isso, a importância de trazer à tona as palavras de ordem que nos capturam, dando-lhe novas significações. Como “[...] o sexo não funciona apenas como norma, mas também faz parte de uma prática reguladora que produz os corpos que governa" (BUTLER, 2002, p. 18, tradução própria) ${ }^{10}$ ressignificar as alocuções que nos capturam é uma forma de resistir, rachando a lógica hegemônica das dicotomias ao dar novas significações aos termos de sujeição,

10 No original: “[...] el sexo no sólo funciona como norma, sino que además es parte de una práctica reguladora que produce los cuerpos que gobierna" (BUTLER, 2002, p. 18). 
que baseados em relações de poder buscam sedimentar determinadas identificações. Se, conforme afirma Butler, o gênero é performático, ou seja, se afirma por convenção e repetição, não havendo desse modo qualquer pureza ou essência biológica no sexo, desestabilizar a linguagem que nos identifica é abrir novos espaços de experiência, já que:

[...] são as instabilidades, as possibilidades de rematerialização abertas por esse processo as que marcam um espaço no qual a força da lei reguladora pode voltar-se contra si mesma e produzir rearticulações que ponham em tela de juízo a força hegemônica dessas mesmas leis reguladoras. (BUTLER, 2002, p. 18, tradução própria) ${ }^{11}$

É assim que a slamer Daisy Coelho “ensina o que é respeito sem gastar nenhum tiro" (COELHO, 2018). Ao elencar as diversas formas de abuso que sofrem as mulheres, faz com que tais ações abusivas se voltem para o próprio opressor. Sua resposta para todas as ofensas é um berro, bem dentro do peito. Metáfora exata para a sua arma, a palavra, com a qual, no poema, realiza "os desejos masculinos imundos" (COELHO, 2018) neles mesmos, rachando a lógica patriarcal de apropriação e sexualização das mulheres. No mesmo sentido, há muitas poesias que desmistificam a importância dada ao falo como fonte de prazer, e reivindicam o desejo feminino, seu direito à experiência com seu corpo, sempre tomado como tabu.

A busca pela desconstrução das imagens opressoras e limitantes, dos papéis inferiorizados impostos e da apropriação dos seus corpos é tema de muitas dessas poesias e se ramifica em variadas vertentes, sempre se valendo de uma fina ironia na desconstrução dos estereótipos femininos. Há por parte delas

\footnotetext{
11 No original: “[...] son las inestabilidades, las posibilidades de remateralización abiertas por ese proceso las que marcan un espacio en el cual la fuerza de la ley reguladora puede volverse contra sí misma y producir rearticulaciones que pongan en tela de juicio la fuerza hegemónica de esas mismas leyes reguladoras" (BUTLER, 2002, p. 18).
} 
uma reapropriação da sexualidade e do próprio corpo, como podemos ver na poesia descontraída e divertidamente irônica de Ingrid Martins (2018), que insiste no seu direito de não usar sutiã, desestigmatizando imagens e palavras, por uma "teta" que tem o direito inclusive de ser "caída", longe dos padrões de beleza oferecidos, e, finalmente, por uma "teta" que para estar livre "não precisa de aval".

Nesse sentido, podemos observar que não há nessas poesias a busca por configurar uma imagem de mulher, e sim, o desejo de desconstruir os rótulos que as capturam para que sirvam aos mecanismos de poder, já que “[...] é a opressão que cria o sexo, não o contrário" (WITTIG, 2006, p. 22, tradução própria) ${ }^{12}$. Inclusive, há por parte das slamers o reconhecimento da importância de considerar nesse discurso os diversos lugares de fala, que um feminismo etnocêntrico e heteronormativo não daria conta. Nesse sentido, se colocam em consonância com as críticas a determinadas posturas dentro da teoria feminista que propiciaram o mantimento de um mito de mulher, privilegiado em sua exclusão das problemáticas da heteronormatividade compulsória e do racismo.

É que a comunidade dos slams, incluindo todos os seus possíveis membros, só pode ser pensada em sua forma paradoxal, ou seja, como comum compartilhado que não suporta a fusão no contato e, em detrimento, reclama o desacordo e a diferença, já que o próprio movimento do viver-junto supõe a desestabilização e o inacabamento. Desse modo, nos lembra que "a comunidade, na contramão do sonho fusional, é feita de interrupção, fragmentação, suspense, é feita de seres singulares e de seus encontros" (PELBART, 2003, p. 33).

Por isso, essas vozes não buscam o apaziguamento de uma configuração subjetiva sólida, imutável e homogênea, que "não permite pensar a produção do novo" (ROLNIK, 1997, p. 6), ao passo que se vê delimitada em uma suposta estabilidade, obstrutora do desassossego e da incompletude que nos forçam a

12 No original: “[...] es la opresión que crea el sexo, no al revés” (WITTIG, 2006, p. 22). 
perscrutar novas cartografias. Ao contrário, elas põem em circulação singularidades que se aproximam do ser qualquer, conforme o pensa Agamben, ou seja, o ser-qual:

recuperado do seu ter esta ou aquela propriedade, que identifica o seu pertencimento a este ou aquele conjunto, a esta ou aquela classe (os vermelhos, os franceses, os muçulmanos) - e recuperado não para uma outra classe ou para a simples ausência genérica de todo pertencimento, mas para o ser-tal, para o próprio pertencimento. (AGAMBEN, 1993, p. 10)

Um ser que não se identifica nos traços atributivos daquele tipo de comunidade que exige a assimilação de uma característica vinculativa que destrói o dissenso e a diversidade irrevogável de nossa condição de ser-com. E é por não reivindicar um lugar, sempre reintegrável (ainda que enquanto desvio) pelo complexo poder-saber, mas, ao contrário, apostar no trânsito, na dinâmica da vida em sua imprevisibilidade, que uma singularidade qualquer se torna resistente e ameaçadora: sem estratégia institucionalizada e regrada de combate, podendo, por sua vez, surgir de qualquer lado, para rizomaticamente conectar outro e outro e outro: mutante devir, que coloca em xeque formas estáticas de percepção.

Por isso, o caráter transgressivo ultrapassa o simples apoio às causas minoritárias ou a derrubada de um poder institucionalizado, e, por conseguinte, aponta para a forma inusitada de resistência, construída na esteira dessa comunidade que vem, na qual se reconhece a pluralidade e a diferença como constitutivas do estar-com e se acredita que "esse encontro, essa chance, esse contágio, mais intenso que qualquer cordão imunitário, é a comunidade daqueles que, evidentemente, só a tem perdendo-a, e perdendo-se, nesse mesmo fluxo" (ESPOSITO, 2003, p. 49, tradução própria) $)^{13}$.

\footnotetext{
13 No original: "[...] este encuentro, esta chance, este contagio, más intenso que cualquier cordón inmunitario, es la comunidad - de aquellos que, evidentemente, sólo la tienen perdiéndola, y perdiéndose, en su mismo deflujo" (ESPOSITO, 2003, p. 49).
} 
Comunidade inoperante e negativa porque não se faz sob a égide de um ser comum a todos, mas aposta na exposição ao outro, na liberdade e na abertura do contágio. Esse é o convite dos slams: afetar e deixar-se ser afetado, em prol de uma socialidade empática, como diria Maffesoli; ou de uma paixão comunitária, que a energia desses eventos torna presente. Na tomada da palavra em estratégias impactantes e criativas da língua, na reapropriação do espaço público, na acessibilidade e na dinâmica ativa de sua circulação, é que a poesia dos slams configura a sua comunidade, que não é una, mas aberta, potencial, plural, inclusiva.

\section{REFERENNCIAS}

AGAMBEN, Giorgio. A comunidade que vem. Lisboa: Editorial Presença, 1993.

BLANCHOT, Maurice. La comunidade inconfesable. Madrid: Editora Nacional, 2002.

BUTLER, Judith. Cuerpos que importan. Buenos Aires: Paidós, 2002.

CENA 7, Michel. Oh pátria safada (2018). Disponível em: https://www.youtube.com/watch?v=cKvpodNwckk. Acesso em: 26 de jul. de 2020.

COELHO, Daysi. (2018). Vou te ensinar o que é respeito sem gastar nenhum tiro. Slam Manos e Minas. Disponível em: https://tvcultura.com.br/videos/65751_vou-te-ensinar-oque-e-respeito-sem-gastar-nenhum-tiro.html. Acesso em: 26 de jul. de 2020.

D'ALVA, Roberta Estrela. Um microfone na mão e uma ideia na cabeça. In: Synergies Brésil n 9, 2011. pp. 119-126. Disponível em: https://gerflint.fr/Base/Bresil9/estrela.pdf. Acesso em: 26 de jul. de 2020.

ESPOSITO, Roberto. Communitas. Origen y destino de la comunidade. Buenos Aires: Amorrortu, 2003.

FREITAS, Daniela Silva de. Slam Resistência: poesia, cidadania e insurgência. Estud. lit. bras. contemp., Brasília, n. 59, p. 1-15, 2020. Disponível em: https://periodicos.unb.br/index.php/estudos/article/view/29317. Acesso em: 09 de abr. de 2021.

MAFFESOLI, Michel. A república dos bons sentimentos. São Paulo: Iluminuras: Itaú Cultural, 2009.

MAFFESOLI, Michel. El tempo de las tribos. Buenos Aires: Siglo XXI editores, 2004. 
MARINHO, Felipe (2018). Coisa tá tão preta que nada mais passará em branco. Slam da Guilhermina. Disponível em: https:/www.youtube.com/watch?v=wlYKFd6EhW0. Acesso em: 25 de jul. de 2020.

MARTINS, Ingrid (2018). Voa bico meu. Slam Manos e Minas. Disponível em: https://www.youtube.com/watch?v=W2MtvjPbxI8. Acesso em: 26 de jul. de 2020.

MIDRIA (2018). Eu quero um fura fila pra cultura e todas as vias de desenvolvimento. Slam sofalá. Disponível em: https://www.youtube.com/watch?v=M5aMP0dl-Oc. Acesso em: 26 de jul. de 2020.

NANCY, Jean-Luc. La comunidad inoperante. Santiago de Chile: Arcis, 2000.

NEVES, Cynthia Agra de Brito. Slams - Letramentos literários de reexistência ao/no mundo contemporâneo. Linha D'Água (online), São Paulo, v. 30, n. 2, p. 92-112, out. 2017. Disponível em: file://C:/Users/babif/Downloads/134615-Texto\%20do\%20artigo-2729121-10-20171027\%20(1).pdf. Acesso em: 08 de abr. de 2021.

OLIVEIRA, Rejane Pivetta de. Literatura marginal: questionamentos à teoria literária. Ipotesi, Juiz de Fora, v. 15, n. 2 - Especial, p. 31-39, jul/dez. 2011. Disponível em: https://pt.scribd.com/document/205165649/Oliveira-Rejane-Literatura-MarginalQuestionamentos-a-Teoria-Literaria-pdf. Acesso em: 08 de abr. de 2021.

PELBART, Peter Pál. Vida capital - ensaios de biopolítica. São Paulo: Iluminuras, 2003.

PENOV, Isabela (2016). Inflamável. Disponível em: https://www.youtube.com/watch?v=cKvpodNwckk. Acesso em: 26 de jul. de 2020.

RANCIÈRE, Jacques. A partilha do sensível: estética e política. São Paulo: Ed. 34, 2005.

RANCIÈRE, Jacques. O desentendimento - política e filosofia. São Paulo: ed. 34, 1996.

ROLNIK, Suely (1997). Uma insólita viagem à subjetividade: fronteiras com ética e cultura. Disponível em: http://www.caosmose.net/suelyrolnik/pdf/sujeticabourdieu.pdf. Acesso em: 26 de jul. de 2020.

ROMÃO, Luiza (2016). A colonização foi um estupro. Disponível em: https://www.youtube.com/watch?v=SCTZK5ejxCY. Acesso em: 26 de jul. de 2020.

WITTIG, Monique. El pensamiento heterosexual y otros ensayos. Barcelona: Editorial Egale, 2006.

VAZ, Sérgio. Manifesto da antropofagia periférica. In: Colecionador de pedras. 2011. Disponível em: http://colecionadordepedras1.blogspot.com/2011/05/arte-que-libertanao-vem-da-mao-que.html. Acesso em: 26 de jul. de 2020.

ZUMTHOR, Paul. Performance, recepção, leitura. São Paulo: Cosac Naify, 2002.

Nota do editor:

Artigo submetido para avaliação em: 17 de fevereiro de 2021.

Aprovado em sistema duplo cego em: 05 de junho de 2021. 